\title{
Alfonso Hernández-Catá
}

\author{
ACLARACION DE UN HECHO
}

$\mathrm{F}^{\mathrm{N}} 1927$ vivía yo en Madrid y estaba a punto de terminar el segundo tomo de El Vigía. Uno de sus tres ensayos trata de "Alfonso Hernández-Catá y el sentido trágico del arte y de la vida". Frente a esos estudios puse sendas y breves notas biográficas a propósito de cada uno de mis retratados: Unamuno, Pérez de Ayala y Hernández-Catá. Al comprobar los datos de la vida del autor de Los frutos ácidos, apresuróse el último a ratificarme algo que ya tenía yo muy oído de sus propios labios: - Nací en Santiago de Cuba, el 24 de junio de 1885. - Pero, Alfonso - le objeté-, Ramón Pérez de Ayala me asegura que usted vió la luz en... - Sí, en Aldeadávila de la Rivera, pueblecito de la provincia de Salamanca, aquí en España. Oyeme, sin embargo, mi historia. Mi padre, Alfonso Hernández Lastras, casó en Cuba con Ėmelina Catá y Jardines. El era Teniente Coronel de Infantería y Esstado Mayor, y era hijo de España; mi madre era cubana. Once hijos tuvieron. Diez de ellos nacidos en América. Por imperativos de los deberes paternos tuvieron que volver a España, llevándome ya mi madre en su seno. Así fué cómo, por motivos de azar, no nací en Cuba. Pero no contaba un año todavía cuando regresamos a Santiago, donde me crié. Mi familia materna es de abolengo revolucionario cubano. Mi abuelo de esa línea fué fusilado por los españoles, y mi único tío varón tomó parte en la guerrà de emancipación desde el primer día. En Santiago estudié en el Colegio de don Juan Portuondo, primero, y en el Instituto de segunda enseñanza, después, hasta los dieciséis años. A esa edad, y por ser hijo de oficial espa- 
ñol, mandáronme, ya huérfano, a Toledo, a un colegio militar del cual me escapé a pie, viniéndome a Madrid. Ya en Madrid pasé privaciones que te he contado otras veces, y estudié en la libre universidad de la vida y de las bibliotecas públicas...

-De todas maneras... no debo publicar un dato erróneo, a sabiendas de que lo es.

-Cierto; pero hazme un favor, un gran favor personal. No me quites, ni siquiera ahí, la ilusión de que soy de Santiago, de que soy cubano. $Y$ cuando yo muera, si muero, como debe ser, antes que tú, aclara el hecho a favor de la estricta verdad.

\section{CONOCIMIENTO DE GALDOS}

Alfonso vió un día a don Benito Pérez Galdós en la Biblioteca Nacional de Madrid. Y se decidió a hablarle. Preguntóle, el de Fortunata y Jacinta, una cosa detrás de la otra. Y después de hacerle confesar que tenia aficiones literarias, le invitó a pasar por su casa y a enseñarle algo de lo que tuviera escrito. Más de una vez Alfonso le llevó un "cuento". E1 maestro lo leía. Le daba una palmadita en el hombro. Y mientras decía, con paternal cariño, "Muy bien, muy bien, muchacho", iba rompiendo en múltiples pedacitos el original, para concluir siempre con el mismo consejo: "Ahora, a escribir otro; y a traérmelo cuando lo hayas terminado". $\mathrm{Y}$ vuelta a asegurarle que debía insistir. $Y$ vuelta a romperle lo nuevo que escribía. Hasta que un día don Benito lo despidió, sin hacerle trizas ni devolverle el cuento, haciéndole prometer que volvería dos días más tarde. Así lo cumplió Alfonso. Recibióle Pérez Galdós con unas pesetas en la mano: --Toma. Envié tu cuento a un periódico, y lo han aceptado. Ahora, a seguir escribiendo por lo menos como la vez última. iA trabajar!

Y Galdós autorizaba, no mucho después, estas palabras que atesoró Alfonso en su memoria y que reprodujo en varios de sus libros: "Hernández-Catá puede y debe dar cualquier día a las letras hispanas una obra maestra". Y por eso, cuando la producción ganóle ecos egregios entre la minoría de la intelectualidad de Cuba, pudo sentenciar Enrique José Varona: "E1 señor Hernández-Catá es el más completo cultivador de las letras en la juventud cubana". 
ESCRITOR Y DIPLOMATICO: $1907-1940$

Después de publicar trabajos breves en diversos periódicos Hernández-Catá dió a la estampa, en 1907, su primer libro: Cuentos pasionales. Casi en seguida contrajo matrimonio con Mercedes Alvarez Insúa ("Lila"), como él hija de español y de cubana. Y regresó a su Antilla donde trabajó de lector de tabaquería y, más tarde, en la Prensa. Hasta que en 1909 fué nombrado cónsul de Cuba en el Hâvre. Desde entonces siguió en la carrera diplomática, desempeñando cargos en Inglaterra, Francia, Portugal, España -donde llegó a embajador bajo la presidencia de Grau San Martín-, Panamá, Chile y Brasil, ejerciendo en las tres últimas como ministro plenipotenciario.

Un despacho del 8 de noviembre, desde Río de Janeiro, trajo la noticia trágica. En el barrio residencial de Botafogo, cerca de la embajada de la Argentina, chocaron dos aviones. Veintidós personas perecieron. Una de ellas era Alfonso Hernández-Catá.

Entre las más frecuentes preocupaciones de Alfonso contaba la de morir tras larga y penosa enfermedad. "Yo nunca seré uno de esos despojos humanos absurdamente apegados a la vida", solía decir. "Si fuera posible contratar estas cosas de antemano, yo firmaría ya por una muerte repentina, o por uno de esos accidentes que apenas nos dan tiempo para saber que moriremos. Pero temo que La Muerte se desconcierta un poco cuando en vez de huírsele se la deja venir a tiempo..."

Alfonso experimentaba el terror a que las rosas se le convirtieran en ceniza. Alfonso rendía culto a la gloria del espíritu. Pero no era un espíritu religioso. Era mitad arte y mitad sensualidad.

En uno de sus libros describe así el instante final del protagonista: “... sintió el golpe esperado; y fué tan fuerte, que comprendió que era el último que iba a darle la vida... Sintió la presencia de su cuerpo en cien dolores y el sabor de su propia sangre en la boca. Eira mucha, mucha, y como si el beberla pudiera infundirle nueva vida, la escupió con la postrera voluntad... Después todo fué paz, viaje ingrávido, sombra". 
SENTIDO TRAGICO DEL ARTE Y DE LA VIDA vido".

"Aquel que no pasó dolor no tiene derecho a decir que ha vi-

La sentencia de Séneca diríase la médula del arte de Hernández-Catá y de la vida de sus criaturas. Estas no se producen en máximas derivadas del filósofo latino de Córdoba. Pero piensan y sienten de aquella manera. Sin dejar, por ello, de pertenecer en ningún momento a nuestra época. Ansian conquistarse el derecho a probar que han vivido. $\mathrm{Y}$ se lo conquistan a fuerza de luchas oscuras, de hondas fatigas, de agónicas tribulaciones. Agobiadas de inquietud y desolación no huyen, acobardadas, de la aspereza humana. La arrostran. $Y$ casi siempre, el afán de combate concluye en definitiva derrota. Sueñan vislumbrar, en las lóbregas profundidades del Destino, una lucecilla prometedora que les aclare un rinconcillo en la tiniebla. Si ríen, cuando ríen, su risa no puede prolongarse. Porque pronto - sedientas de vivir su dramático sentimiento- se mezclarán, ineluctablemente, con las hadas del dolor y el exterminio.

La obra de Hernández-Catá carece de elemento cómico. ("El mundo es una comedia para los que piensan y una tragedia para los que sienten". Lo ha dicho Horace Walpole).

Así se comprende mejor que, en la obra de Hernández-Catá, hallemos otro elemento hijo del contacto del sentimiento con la realidad: la ironía. "La ironía es un dolor que no acierta a llorar y sonrie: la ironía es un veneno dulce". He ahí cuán bella y sutilmente la define el propio creador que comento, por labios de uno de estos personajes.

En ninguna página de Hernández-Catá priva la crueldad gozosa, como en muchas de Swift y de Voltaire y en no pocas de Eça de Queiroz y Dostoiewsky. Pero con frecuencia destila la ironia en ellas su matiz de impotencia. $Y$ entonces trae al recuerdo la definición realista de Litrẻe: "La ironía es un perro que no puede morder y enseña los dientes".

\section{LA NOTA NUEVA}

Una de las más asiduas ambiciones literarias de HernándezCatá era traer la nota nueva a sus ficciones. No quiero decir -ni 
se debe entender - que esa novedad se refiere a las escuelas, según la tendencia en boga en el momento de escribir. Contrariamente, Alfonso menospreció siempre el snobismo. Lo que dice de sus versos, en el único libro del género que publicó - Escala- aplícase a su arte en general: "Versos sinceros ajenos a propósitos de deslumbrar y al triste designio de rebajar el rango del arte - hecho de locura de eternidad- a lo efímero de las modas, entre los de ayer y los de hoy, no hallaréis, lector, diferencia excesiva. $\mathrm{Ni}$ extremos extatismos, ni malabarismos, que ponen al arte en riesgo de caer en habilidades baladies. No habiendo sentido el imperativo genésico de crear nuevos moldes, no he querido fingirme la necesidad de romper los antiguos... En todo tiempo hubo, por fortuna, poetas; $y$ en todo tiempo en torno a cada verdadero innovador, eunucos salteadores y bullangueros se entregaron a imitaciones estériles". Ia nota nueva era en su obra de contenido. Aspiraba a enriquecer el repertorio temático de la novela y del cuento en su idioma.

Pelayo González, el segundo de sus libros en orden cronológico, reproduce un tono desconocido hasta su día en la literatura española. Sus precedentes hay que buscarlos en la inglesa: Sartor Resartus, de Carlyle; y en la francesa: La Rôtisserie de la Reine Pedauque, de Anatole France.

Aunque la literatura española contaba con páginas representadas por animales, como las del coloquio de los perros cervantinos, carecía de una obra amplia totalmente dedicada a los irracionales en tono ficticio. Aquí acudió, también, Hernández-Catá, mediante su creación de La casa de fieras. La ironía del autor subraya, en este bestiario, el hecho de que el plano inferior es el del animal social, no el del irracional. Basta conocer la opinión que tiene la hiena de sí misma: "Yo como cadáveres igual que el hombre y el hombre me detesta y me pone siempre de odioso ejemplo. iNo lo entiendo! Será porque no los como con tenedor". De convenir en que, a veces, ironía y melancolía son hermanas, bien lo ilustra el pensar del pato que alienta en La casa de fieras: "Poeta, demasiado poeta. Unas veces sueño con ser cisne y otras con ser faisán, y como la envidia enferma el hígado, el hombre ha hecho del mío uno de sus manjares predilectos". Preocupados, otra vez -y siempre- con el hombre - su más grande enemigo- estos animales no olvidan los peligros, los engaños $y$ las traiciones a que frecuentemente somete 
al hombre su compañera. $\mathrm{Y}$ dice el oso: "Tardío, frío, paciente, y, sin embargo... Mis brazos son casi tan temibles como los de algunas mujeres".

"E1 tercer Fausto", una de las cuatro narraciones que integran el Libro de amor, apoyándose inicialmente en la sed rejuvenecedora ansiada para la especie humana por el doctor Voronoff, supera -en riqueza imaginativa, en fantasía y audacia - todas las ambiciones biológicas del buen Mefistófeles contemporáneo.

Al protagonista de "E1 aborto", novela breve incluida en $L a$ voluntad de Dios, se le ocurre esta insólita teoría, luego de haber tomado parte como soldado en la Primera Guerra europea: que así como un ser lega a otro sus bienes materiales, pudiera legarle, también, los espirituales y técnicos. ¿Cómo? Mediante increíbles injertos hechos en músculos recién amputados, primero, y en organismos vivos, después: teoría que franquearía nuevos caminos al hombre, una vez lograda en la práctica. Héla aquí formulada: "Y si ahora se hereda una tierra o una casa o un título, en un mañana muy cercano podrá también legarse un curso de electrotecnia o diez años de trabajos filosóficos. Y el hombre que reciba la herencia, partirá desde el punto final de ese legado, hacia arriba; y por ello, el progreso de la Humanidad pasará de progresión aritmética a progresión geométrica". El protagonista de "El aborto", el profesor Henrich Teufelsdroeckl, así como su antiguo maestro, Herman Lussenhop, que le auxilia en sus investigaciones, caen, por fin, como tantos héroes científicos de la vida real, inmolados por las muchedumbres supersticiosas. Humorismo. Pero humorismo trágico, tratándose de la obra de un escritor sobrecargada de tintas oscuras. Y si Pelayo González nos hizo recordar al Sartor Resartus, ese apellido, Teufelsdroeckl, vuelve a remover el recuerdo carlyleano dentro de las letras españolas.

En "La madrastra", otra de sus ficciones breves, HernándezCatá apartóse de una costumbre psicológica general. En vez de hacer de la madrastra el tipo de intrusa, objeto de odio, cuando no de escarnio o desdén, truécala en flor de cariño, de adhesión y respeto que la ennoblece y la acerca a su hijastro. La eficacia del logro recuerda al E,dgar Allan Poe que en su soneto "To My Mother", dedicado a su suegra, rectifica prejuicios tradicionales gastados ya en cuentecillos del peor gusto. 
En "La piel" (de Los frutos ácidos) se estudia por primera vez en las letras españolas el error divino de haber insuflado un espíritu de elección en un cuerpo de raza postergada. La tragedia de un negro que, hijo de blanco, siente inclinación por todo lo noble, por todo lo justo, por todo lo bello. Sensibilidad exquisita, en suma, en choque trágico con un medio hostil. Porque su epidermis, contrastando en color con su espíritu, cerraba para Eulogio Valdés -que asi se llama el protagonista que se adelantó en apellido y en drama a El negro que tenía el alma blanca, de Alberto Insúa-todas las puertas ideales abiertas por su inteligencia, ávida de libertad y devota de perfecciones.

Animado -sin duda - por el triunfo artístico que acusa "La piel", y preocupado, frecuentemente, con el problema de las luchas raciales, Hernández-Catá escribió más tarde, atento siempre a la nota nueva, "El drama de la señorita Occidente" (que forma parte del Libro de amor), "Los chinos" (uno de los cuentos de Piedras preciosas) y "Cuatro libras de felicidad" (narración breve que da título a una de sus obras postreras).

La última novela que produjo Alfonso Hernández-Catá, El ángel de Sodoma, afirmóle en su intención deliberada de rehutir el tópico novelesco. En otras palabras: se adentró allí, nuevamente, por campos creadores inexplorados hasta entonces en la ficción española. Aquí presenta su autor un caso de homosexualismo que culmina en tragedia. Hasta la fecha en que apareció Eil ángel de Sodoma, el tipo patológico que en la ficción arrostra HernándezCatá - como antes la suegra y la madrastra- motivó comentarios crueles. O movió a risa, presentado en grotesca y burlona caricatura. Desde 1928, luego de conocer la pasión y muerte de José María Vélez-Gomara (protagonista de la novela), el lector español conocería un nuevo matiz de conciencia: el del sér predestinado a caer en el peor vicio para que pudo nacer el hombre; y que, después de luchar patéticamente contra sí mismo -en agónica renunciación que le amenaza con quedar superada - opta por la muerte. Caso opuesto al de The Well of Loneliness, de Radclyffe Hall, en las letras inglesas, nunca siente tampoco el lector de moralidad limpia, ante el drama de José María, la menor repugnancia. Jamás piensa que, de haber tomado tal o cual precaución, en apuro del albedrio, hubiera podido curarse de su inclinación, en vez de sentir el imperativo 
erótico de la tendencia sexual que sólo halla fin con la muerte: cuando el hombre - José- en su postrera trinchera de dignidad, mata en él a la mujer - María - en su primera blandura de gozosa esperanza. Integra autofrustración.

\section{ESTILO. LA MUSICA DEL MAR}

Hay, en la prosa de Hernández-Catá, una exaltación magnífica y una armonía sinfónica como de voz de mar. Recuérdese que sus sentidos se pusieron en contacto con el mundo en una isla. Y nótese que sus descripciones más fuertes, rítmicas y apasionadas en el mar casi siempre se inspiraron. Ya en la narración "La magia de la Venus plebeya", inserta en Pelayo González, celebra el regocijo con que, luego de las noches de borrasca, aparece el faro de la distante

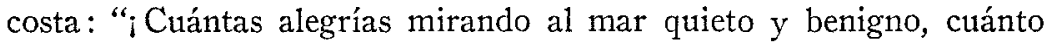
júbilo al ver las barcas inclinarse con gracia, henchidas las velas, y al ver regresar a la rada los barcos que habían derrotado a la tempestad, desarbolados como raros pájaros gigantescos!"

Marinos y navegantes viven, inquietos y aventureros, en muchas de sus páginas. Y la voz del mar, evocando la de tierras lejanas, se repite con frecuencia: "Poco después, la popa del Palinuro quedó en silencio, y al cabo de un rato, de la proa llegaron nuevas voces dominadas por la gangosa melodía que suavemente subió y se expandió en la serenidad de la tarde. Erra una melodía lenta, acompañada de modo monótono, pobre; y, sin embargo, parecían sintetizarse en ella todos los hechizos de la tierra. Por el hilo de aquella melodía, la tierra tiraba suavemente de los once hombres que se desprendieron de su seno para vivir en un elemento extraño. Una dulzura de hogar, un temblor de amor, una fragancia inefable de flores, de hojas, de llama de retamas, de jardín despertado por las primeras lluvias abrileñas, se exhalaba de aquella tonada vulgar".

Y si en "La patria azul" (en La voluntad de Dios), de donde tomo ese ejemplo, recuerda a la tierra desde el mar, en "Bajo la luz" (del Libro de Amor), recuerda al mar desde la tierra: "A mi, desde la infancia, me atrae el mar, me tienta el mar. A veces, tierra adentro, he sentido su sal y su yodo en la boca y en sus desordenados vientos en la fantasía. Los relatos náuticos me fascinan. Si hay otras vidas, yo he sido ya marino o me aguarda aún la dicha 
de poderlo ser. Nada del mar me es indiferente... Preguntadme la fecha de los grandes naufragios, las hazañas de los grandes piratas, y hasta las más complicadas maniobras de un velero de cinco palos, y veréis cómo no me equivoco... i Mar, que tienes de madre y de madrastra por cuanto meces y por cuanto azotas; tuyo soy; $y$ aunque nunca he ido sobre ti, en tus playas y lejos de ellas parezco uno de esos caracoles llenos de tu vasta resonancia, en cuyas entrañas nacarinas cantan siempre las sirenas de Ulises ...."

Leídas las páginas de La muerte nueva, uno de los más ambiciosos libros de este novelista, escribió Gabriel Alomar: "Quisiera poner aquí todos los elogios al estilo que alcanza en La muerte nueva Hernández-Catá". Y refiriéndose, finalmente, a su prosa, observó Jorge Mañach: "La prosa de Hernández-Catá, henchida más que maciza; clara, limpia, voluntariosa, pero capaz de afiligranarse sólo según ley, como los bellos cuarzos".

\section{HERNANDEZ-CATA Y EL CUENTO}

Estableciendo relación directa entre la época en que vivía y el género literario de su preferencia, Hernández-Catá sustentaba esta teoría: "Para épocas extáticas en que el movimiento y la aventura eran excepcionales, escribiéronse las novelas latas, propicias a las horas de tedio; para hoy que estamos enfermos de velocidad, sean los cuentos y las narraciones breves; que no de las dimensiones lineales, sino del poder profundizador del artista, dependerá dotarlos de virtud para producir, sin mengua, una alegria, un dolor, un anhelo, un paisaje o un Universo íntegro. En las pupilas de Cleopatra veía Antonio el inmenso Nilo lleno de galeras... No puede dudarse, pues, de la capacidad de un género que así concilia el ritmo acelerado de estos tiempos con la aptitud de recibir y revivir cuanto la observación, la fantasía y el pensamiento otorgan a las obras imaginativas".

Refiriéndose a Una mala mujer (la séptima, cronológicamente, de las obras de Hernández-Catá), donde hay más de un cuento inolvidable, como "La institutriz", escribió José Enrique Rodó: "Sus cuentos me emocionan y me dejan una estela de recuerdos y de sugestiones cual si fueran episodios vivos o tenaces imágenes de un ensueño de belleza, de exaltación, de amargura, cuya clave sería la 
interpretación de la vida, árbol que entre el follaje innumerable oculta un tronco enjuto por donde circulara toda la savia de la verdad única".

Con motivo de los veintiuno que integran Los siete pecados, tan alabados por Emilia Pardo Bazán, escribió Enrique Díez-Canedo: "En ellos, muchas veces, por debajo de la anécdota impresionante, se siente el latido de una pasión en que se traduce a lenguaje de eternidad lo efímero de los gestos humanos".

Al aparecer Piedras preciosas, dijo Eduardo Grómez de Baquero (Andrenio): "Aunque Hernández-Catá ha cultivado con fortuna todas las formas narrativas, o, si se quiere, todas las dimensiones de la novela, sobresale en las formas breves. En las novelas cortas y en los cuentos están sus mejores relatos, y suele mostrar, en ellos, un arte seguro de condensación y de selección de elementos artísticos".

Y Eduardo Barrios, al prologar, en Santiago de Chile, la colección de Sus mejores cuentos, de Hernández-Catá, resumía: "En ninguno de los géneros literarios, como ell el cuento, se advierte mejor la verdad de que cada motivo exige su forma propia. El buen cuentista sabe que, si no acierta con esa forma única que calza perfectamente al asunto, éste se malogra o pára, a lo sumo, en aceptable remedo. Hernández-Catá posee como pocos este dón de distinguir la forma propia de los asuntos que la vida, suya, ajena o universal, le brinda".

\section{UNIVERSALIDAD Y CUBANISMO}

El no haberse limitado dentro de las demarcaciones del color local; el haber cruzado varios mares y conocido diversas tierras; el haberse lanzado en audaces saltos creadores desde un trampolin que supo de plurales espacios es responsable de que al hablarse de la novela y del cuento hispanoamericanos, no se mencione siempre el nombre de Alfonso Hernández-Catá. ¿Por qué estrechar la literatura dentro de las demarcaciones fronterizas? De subsistir, en general, semejante criterio entre los comentaristas de las letras hallaríamos a Inglaterra sin la mejor parte de Shakespeare: porque no fueron, en muchos casos, hombres y lugares de su tierra los que dieron carácter y escenario a sus dramas. Otro tanto ocurriria en 
Francia con el más francés de sus escritores del XVIII: con Voltaire. Porque las criaturas de sus narraciones y los sitios por donde vagaban no eran de la propia patria del de Candide, del de La princesa de Babilonia, del de Zadig.

La palabra justa la escribió Stefan Zweig, cuando, refiriéndose específicamente a Hernández-Catá, y hablando en Río de Janeiro a nombre de los escritores de Europa, preguntaba: “...¿quién, en resumidas cuentas, sirve mejor a una nación que aquel que la saca de. sus fronteras, que conecta y une su literatura con la literatura del mundo, y, al elevar su propio rango, eleva así el rango de su patria?"

No hay que olvidar, sin embargo, que en la Mitología de Marti, dando también la nota nueva dentro de las apologías consagradas al claro varón de su Antilla, recrea Hernández-Catá, idealmente, la egregia figura del apóstol americano. Renuncia a los hechos domésticos e históricos, para concebirlo con otra dimensión entranable, que se aparta del hecho específico y que se eleva a planos sensibles de' poesía superior; pero encuadrado siempre dentro del marco telúrico inconfundible, que evoca con infinita ternura. Mas, aunque asi no fuera, aunque no tuviera Cuba esa Mitología ni tantas alusiones evocadoras en no pocos libros de Hernández-Catá, a medida que se estudie su producción se irá descubriendo que el artista conocedor de que la inconformidad, sombra del alma, engendra todos los progresos, fué sembrando, en el fecundo descontento de su creación, semillas de novedosos pétalos cuya gloria se reflejará en la tierra a la que, según el mismo Stefan Zweig, le sirvió, en sentido literario y diplomático, "maravillosamente".

Lo que en Unamuno era metafísica, dogma, horror ante el sér desintegrado, fué, en Hernández-Catá, aventura intensa. Pero aventura humana, de arcilla y de ensueño indivisibles. $\mathrm{Y}$ su pesimismo, que provenía de la "carne triste", calificada por Mallarmé, apesadumbró en él, con frecuencia, la luz deslumbrante de su tierra, transmutándola en esa atmósfera, triste y nubosa, propia de los nórdicos Knut Hamsun y Strindberg. De ahí que casi todos sus entes de ficción puedan decir con Hebbel: "Somos tan pequeños como nuestra alegría, pero tan grandes como nuestro dolor".

Siempre creyó este hombre que la miel está en el viaje, no en la cima; en el esfuerzo, no en el resultado... 
Si el futuro estudia su obra, con primor y con justicia, acaso vea, como lo anticipó uno de sus apologistas, que la sombra de su labor se alarga viva hacia el porvenir.

José A. BALSEIRO, Barceloneta, Puerto Rico. 